\title{
Emotion Regulation, Personality and Social Adjustment in Children with Autism Spectrum Disorders
}

\author{
Nathalie Nader-Grosbois, Stéphanie Mazzone \\ Psychological Sciences Research Institute, Université Catholique de Louvain, Louvain-la-Neuve, Belgium \\ Email: Nathalie.Nader@uclouvain.be
}

Received 28 August 2014; revised 21 September 2014; accepted 12 October 2014

Copyright (C) 2014 by authors and Scientific Research Publishing Inc.

This work is licensed under the Creative Commons Attribution International License (CC BY). http://creativecommons.org/licenses/by/4.0/

c) (i) Open Access

\begin{abstract}
The study examines how emotion regulation and emotion dysregulation in 3 - 12 years old children with autism spectrum disorders $(n=39)$ are linked with the five factors of personality and their social adjustment. Children were assessed by means of the Differential Scales of Intellectual Efficiency-Revised edition (EDEI-R). The teachers have completed the CARS-T, the Bipolar Rating Scales based on the Five Factor Model (EBMCF) and the French version of Emotion Regulation Checklist (ERC-vf) and a Social Adjustment scale (including items related to Theory of Mind, EASEToM, and related to social rules, EASE-Social-Skills). Positive and significant correlations are obtained between emotion regulation scores and verbal developmental age, personality factors of openness, agreeableness, and extraversion. The emotion dysregulation score is negatively and significantly linked with the factor of emotional stability, but positively and significantly linked with extraversion. Moreover, emotion regulation scores are positively and significantly linked with scores in social adjustment. Linear regression by stepwise shows that both extraversion and agreeableness explain $66.5 \%$ of the variance of the emotion regulation score; and extraversion, agreeableness and emotional stability explain $68.3 \%$ of the variance of the emotion dysregulation score. The openness explains $55.9 \%$ of the variance of the EASE-ToM score. Both agreeableness and extraversion explain $61.6 \%$ of the variance of the EASE-Social Skills score.
\end{abstract}

\section{Keywords}

Emotion Regulation, Emotion Dysregulation, Personality, Social Adjustment, Autism

\section{Introduction}

Emotional regulation corresponds to processes by which an individual assesses, control and modify his spontaneous emotional responses, by using various strategies, in order to accomplish his goals or in order to express 
socially adequate emotional behaviour (Eisenberg, Fabes, Guthrie, \& Reiser, 2000; Gross \& Thompson, 2007; Thompson, 1994). The emotion regulation has been defined "as the process of initiating, avoiding, inhibiting, maintaining, or modulating the occurrence, form, intensity, or duration of internal feeling states, emotion-related physiological, attentional processes, motivational states, and/or the behavioral concomitants of emotion in the service of accomplishing affect-related biological or social adaptation or achieving individual goals" (Eisenberg \& Spinrad, 2004: p. 338). Emotional regulation presents a value of social communication, in which emotions have a function of organizing relationships of individuals to their environment, and are the basis of socialisation (Eisenberg et al., 2000; Thompson, 1994). Shields \& Cicchetti (1997: p. 910) distinguished emotion regulation corresponding to appropriate expression of emotions according to situations, empathy, and emotional selfawareness, and the "Lability/Negativity or emotion dysregulation" as "a lack of flexibility, mood lability, and dysregulated negative affect". This conceptual distinction is major for the assessment because it induces the importance to differentiate, in profiles of children with and without developmental disorder, both their abilities and difficulties to regulate their emotions, in intra- and inter-personal aspects (Adrien, 1996, 2005; Cole, Michel, \& Teti, 1994; DeGangi, 2000; Gomez \& Baird, 2005; Mazefsky, Herrington, Siegel, Scarpa, Maddox, Scahill, \& White, 2013; Nader-Grosbois, 2011b, 2012; Samson, Phillips, Parker, Shah, Gross, \& Hardan, 2014). According to Werner \& Gross (2010), emotion dysregulation is the inability to flexibly respond to and manage emotions. Given the complexity of this construct, some researchers have focused on emotion sensitivity, others on affective intensity or affective lability, still others on emotional vulnerability... According to integrate these disparate approaches, emotion dysregulation could be viewed as a process incorporating multiple interactive components (Werner \& Gross, 2010).

A significant amount of literature, including theoretical models and empirical studies, has been developed about emotional and social competences in typically developing (TD) children, in children presenting externalizing behavior disorders or intellectual disabilities. In order to better understand their developmental and functional dynamic and to conceive adapted intervention, the interrelations between understanding of emotions, of mental states (Theory of Mind, ToM), social information processing, emotion regulation, abilities in social interactions, and social adjustment are studied (see detailed review in Baurain \& Nader-Grosbois, 2013; NaderGrosbois, 2011a). The impact of individual factors (chronological age (CA), mental age (MA), developmental age, diagnosis, disability...) and of familial and environmental factors on these processes and on their links is also investigated. Although there is abundant literature about autism spectrum disorders (ASD) on specificities in emotional expression and recognition, in emotional cognition, in ToM and in social interactions in link with their diagnosis criteria (see detailed review in Nader-Grosbois \& Day, 2011), the conceptualization and empirical studies focused on self-regulation, emotion regulation and dysregulation and their roles in their social (in)abilities have been developed more recently.

Among individual factors that could influence socio-emotional competences, including emotion regulation, the factors of personality should be more investigated in atypically developing children, particularly in children presenting ASD. Recently, based on The Five Factors Model of personality, some instruments have been conceived to assess factors of personality in children, from preschool age, that could be used about atypically developing children.

The present study aims at identify links between the five factors of personality in children with ASD $^{1}$ and their emotion regulation or dysregulation. It examines also the links between personality factors, their emotion regulation or dysregulation and their social adjustment.

\section{Emotional Expression, Emotional Responding and Emotion Regulation in Children with ASD}

\subsection{What about Emotional Expression and Responding in Children with ASD?}

Because of cognitive specificities in the way young children with ASD interpret their own emotional experiences and those felt by others, they are unlikely to convey their emotions conventionally (Saarni, 1999). Even if children with ASD are sensitive to emotional cues emitted by others, such as the distress (Nadel, Croué, Mattlinger, Canet, Hudelot, Lécuyer, \& Martini, 2000; Sigman, Kasari, Kwon, \& Yirmiya, 1992), they have difficulties to display in an adequate way their emotional expressions (Brun, Nadel, \& Mattlinger, 1998; Loveland, Tunali-

\footnotetext{
${ }^{1}$ Not including High functioning ASD or Asperger.
} 
Kotoski, Pearson, Brelsford, Ortegon, \& Chen, 1994; Yirmiya, Sigman, Kasari, \& Mundy, 1992). Compared with children matching on their MA, preschoolers with ASD do not display less emotion or facial expression but they react more intensively during social interactions or when they are watching video sequences illustrating emotional expressions in others (Capps, Kasari, Yirmiya, \& Sigman, 1993). Yirmiya, Kasari, Sigman, \& Mundy (1989) observe that although children with ASD show similar quantities of positive and negative emotions to TD children, their facial movements express more than one emotion and they display more combinations of incongruous facial movements. Poor emotional expressiveness in children with ASD is emphasized, in comparison with TD and Down syndrome children (Kasari \& Sigman, 1996; Loveland et al., 1994). At preschool age, children with ASD show poorer emotional coordination and timing of affect during social exchanges, in comparison with children matched on their MA and their CA (Scambler, Hepburn, Rutherford, Wehner, \& Rogers, 2007).

At school age, they respond to others' emotional expressions with less concern and comforting behaviour or empathic behaviour; they do not easily share their own affects or emotions with partners (Bacon, Fein, Morris, Waterhouse, \& Allen, 1998; Corona, Dissanayake, Arbelle, Wellington, \& Sigman, 1998; Dawson, Webb, Carver, Panagiotides, \& McPartland, 2004; Kasari, Sigman, Mundy, \& Yirmiya, 1990; Sigman et al., 1992). This weak responsiveness to others' emotions remains stable over a 5-year period (Dissanayake, Sigman, \& Kasari, 1996). This weakness of empathy in children and adolescents with ASD has been widely reported and empathic responses in social scenarios are specifically trained (Argott, Buffington Townsend, Sturney, \& Poulson, 2008; Charman, Swettenham, Baron-Cohen, Cox, Baird, \& Drew, 1998; Hudry \& Slaughter, 2009; Travis, Sigman, \& Ruskin, 2001). However, empathy behaviour may vary according to individuals (McGovern \& Sigman, 2005) and according to specific emotional context, the degree of familiarity of partners (Hudry \& Slaughter, 2009). At school age, children with ASD share their emotional expressions with others in a less spontaneous way in social interactions in contrast with TD children or children with intellectual disability (Bieberich \& Morgan, 2004) notably in unstructured situations (Kasari, Sigman, \& Yirmiya, 1993). The combination between their emotional expression and eye contact and the reciprocal expressiveness face to their caregiver's expressions, are also less displayed by them, in comparison with control groups (Dawson, Hill, Spencer, Galpert, \& Watson, 1990b). So, they appear less expressive because they show more often neutral, flat or idiosyncratic expressions, in comparison with MA-controls, and this continues later in their lives (Czapinski \& Bryson, 2003; Hobson \& Lee, 1998; Kasari et al., 1990; Loveland et al., 1994). Sometimes, children with ASD display more often happy expressions in solitary or unpleasant situations than in social situations (Whitman, 2004).

According to Begeer, Koot, Rieffe, Meerum Terwogt, \& Stegge (2008), in comparison with TD children, children with ASD should present similar elementary emotional expressiveness and experiences, but they should differ in the inter- and intra-personal integration of their emotions. These authors specified that "empirical evidence found for the influence of age, intelligence and context factors on the level of emotional expressiveness in children and adolescents with ASD refines the marked impairments of emotional expressive behaviour that are suggested in the diagnostic manuals” (Begeer et al., 2008: p. 346).

\subsection{What about Emotional Regulation in Children with ASD?}

Emotion regulation impairments are frequently emphasized in profiles of children with ASD (Cole et al., 1994; Dawson \& Lewy, 1989; Dawson, Osterling, Meltzoff, \& Kuhl, 2000; DeGangi, 2000; Gomez \& Baird, 2005; Loveland, 2005; Prizant, Wetherby, Rubin, \& Laurent, 2003; Samson et al., 2014; Southam-Gerow \& Kendall, 2002; Tardif, Lainé, Rodriguez, \& Gepner, 2007). These authors found a deficit in expression, in modulation and in internal and external regulation of emotions, due notably to neurophysiological factors. It results that they are at risk for experiencing heightened states of emotional arousal causing anxiety, agitation (often interpreted as behavior problems) and limiting their availability to interact or to learn, according to Prizant et al. (2003). Consequently, they are described as easily stressed, anxious, fearful or non-compliant. They have difficulty in self-regulating their emotions when their feelings become excessive (Whitman, 2004). At preschool age, children with ASD, barely modify their emotional reactions in response to others during social exchanges (Konstantareas \& Stewart, 2006). Especially, when they are faced with frustration, these children with ASD may engage in inadequate or not effective strategies (such as, more avoidance and venting strategies) to regulate their emotions, in comparison to matched peers (Jahromi, Meek, \& Ober-Reynolds, 2012; Konstantareas \& Stewart, 2006). Recently, Jahromi, Bryce, \& Swanson (2013) find that children with high functioning autism are rated 
significantly lower in emotion regulation (measured by Emotion Regulation Checklist) and effortful control than their TD peers matched on their expressive language.

However, to study in nuanced way specificities in emotion regulation of children with ASD, it needs to consider co-regulation between them and their partners, including their parents. In an experimental study comparing to both control and joint attention intervention conditions, Gulsrud, Jahromi, \& Kasari (2010) observe variability in the intensity of negative expressions and in the number of distress episodes in toddlers with ASD, but almost all display an increase of negative arousal during play interactions with their mothers. This observation is interpreted as evidence of profiles of dysregulation. However, these children engage in a range of emotion regulation strategies, characterized as appropriate active strategies (distraction, avoidance and tension release) and constructive strategies (orienting to mum and seeking assistance). Like TD toddlers, they are able to request maternal support and assistance; however, they make less frequent use of sophisticated verbal strategies such as symbolic/verbal self-soothing (which may be impeded by their low expressive language level-less than 20 months). Emotion regulation strategies are used significantly more by toddlers with ASD during episodes of negativity than non-negativity. In addition, mothers of toddlers with ASD engaged (as also reported for mothers of TD toddlers) in a variety of emotion regulation strategies when the child is in distress, from active strategies (redirection, prompting, physical behaviours) to vocal comforting strategies (vocal soothing and reassurance). They continue to use active strategies throughout the intervention more frequently than mothers of TD children. Moreover, specific characteristics in the child with ASD and the mother are associated with emotion regulation outcomes.

These specificities in expression and regulation of emotions in children with ASD are notably explicable by their difficulties described in an abundant literature in: recognition of facial emotional expressions, identification of emotions, understanding of emotions, decoding of ToM precursors (such as joint attention), ToM and socioemotional information processing (Begeer et al., 2008; Downs \& Smith, 2004; Hobson, 1993; Lacroix, Guidetti, Rogé, \& Reilly, 2009; Nader-Grosbois \& Day, 2011; Tardif et al., 2007). Some studies reveal that poor emotion regulation or emotion dysregulation is linked or predict social maladjustment in children with ASD, or report positive significant links between their emotion regulation and prosocial peer engagement, cooperative participation, social responsiveness, social skills and mobilization of ToM in daily life, social adjustment behavior (Jahromi et al., 2013; Nader-Grosbois, 2011a, 2011b; Nader-Grosbois, Baurain, \& Mazzone, 2012; Samson et al., 2014).

Theoretical support for emotion regulation deficits in children with ASD comes from conceptions and studies on self-regulatory processes (including executive functions). Several authors postulate that there is a deficit of emotional regulation depending from a major impairment of self-regulation that explains a set of inabilities in infants, children and adolescents with ASD in their social interactions and social adjustment (notably, Adrien, 1996, 2005; Gomez \& Baird, 2005; Konstantareas \& Stewart, 2006; Loveland, 2005; Nader-Grosbois, 2011b; Trevarthen, 1989; Prizant et al., 2003; Whitman, 2004).

Trevarthen (1989) suggests that ASD is due to an early basic deficit in the production of emotions and of emotional regulation in reaction to environmental stimulations. He hypothesized a biological origin of this impairment; a dysfunction of central regulator systems. Children with ASD do not feel emotions related to exchanges initiated by others or to experiences they have towards objects. Moreover, poor or absent or paradoxically excessive emotion in children with ASD does not play its role of regulator, as search, product, maintain, inhibit, and interrupt behaviours oriented to others or to objects.

In Adrien's perspective (Adrien, 1996, 2005), all deficits in regulation processes in ASD are explained by a "functional and developmental dysregulation". He explains that this deficiency in emotionality in children with ASD appears more in situations requiring regulation: breaking off, maintaining, amplifying or reducing the emotional affects. They prefer to resist to change and to conserve their initial state, notably in order to avoid social situations which are sources of emotional amplifications or reductions, requiring regulation. The Adrien's view (Adrien, 1996, 2005) is supported by numerous clinical observations and results of empirical studies, showing dysregulation in children with ASD in sensory-motor and cognitive domains (including symbolic play), in socio-emotional problem-solving or interactive situations mobilizing joint attention and in school activities (Blanc, Adrien, Roux, \& Barthélémy, 2005; Nader-Grosbois, 2007; Remy, 2013; Seynhaeve \& Nader-Grosbois, 2008; Seynhaeve, Nader-Grosbois, \& Dionne, 2008); this dysregulation may be reduced by means of an adapted intervention, such as the program IDDEES (Gattegno, Abenhaim, Kremer, Castro, \& Adrien, 2006). 
In his model "the development of autism: a self-regulatory perspective”, Whitman (2004) emphasizes the essential role of self-regulation in several processes of development and of functioning in children with ASD, including emotional and social areas. Whitman (2004: pp. 158-160) suggests that emotions and self-regulation must be considered in conjunction because they can be either risk or protective factors in social adjustment of children with or without ASD. He specifies that children with ASD may be vulnerable to stress if their arousal and stateregulation dysfunction, if their self-regulatory system is poorly developed and if environmental stressors are too intense or prolonged. His theory describes also that the emotions in children with ASD indirectly influence the development of self-regulation through their impact on sensory, motor, social, cognitive, and language or communicative processes. Not only, these latter processes directly affect the development of self-regulatory behaviour (through the tools they provide for self-regulation) but self-regulation provides individuals the capacity to control their emotions. On the basis on these conceptions and a set of studies, Nader-Grosbois (2011b) proposed an integrated approach of these processes of self-regulation, dysregulation and emotion regulation in order to better understand psychological functioning and development in children with ASD.

In a recent review of literature, Mazefsky et al. (2013) examined how emotion regulation was approached in people with ASD and the role of emotion regulation and of emotion dysregulation in this clinical population. They revealed that although poor emotion regulation is shared with other atypically developing children, specificities in ASD could be identified to explain emotion dysregulation. On the basis of this review, these authors summarized factors that may contribute to emotion dysregulation in ASD: function and motivation of emotion (less organized and goal-oriented emotion, internally driven responses), degree of negative vs. positive affect (greater or more intense baseline levels of negative affect, irritability), cognitive factors (poor problem solving, rigidity, impaired perspective taking...), information processing and perception (difficulty filtering environmental stimuli and identifying social and emotional cues...), psychiatric conditions (mood and anxiety disorders...), neural circuitry (abnormal amygdala/prefrontal cortex function and connectivity, affecting emotion regulation and social behaviour) and altered physiological activity (hyperarousal...) (Mazefsky et al., 2013: pp. 684-685). These authors emphasized also that these processes of emotion regulation and emotion dysregulation are too little known in young children with ASD.

Research should continue to explore factors associated with individual differences in emotion regulation for children with ASD and how the degree to which emotion dysregulation could explain a part of heterogeneity in children's social (in)abilities. In order to investigate individual differences in emotion regulation and dysregulation and in social (mal)adjustment, it seems particularly relevant to investigate the impact of family factors, such as parents' strategies of "socialization of emotions" (reactions toward their child's emotions, conversations about emotions, co-regulation between parents-children) (Gulsrud et al., 2010; Mazzone \& Nader-Grosbois, 2014); and the impact of individual factors, such as the factors of personality (beyond cognitive factors and level of severity of ASD...).

\section{Factors of Personality and Temperament in Children}

\subsection{Which Interest to Approach the Five Factors of Personality in Children and How They Are Defined?}

Recently, studies examined individual differences in TD children as resulting of personality factors rather than temperament that are conceived progressively as two distinct conceptual systems inducing two types of measures (De Pauw, Mervields, \& Van Leeuwen, 2009; Grist \& McCord, 2010; Kohnstamm, Halverson, Mervielde, \& Havill, 1998; Litty, 2007). Traits of personality refer to "individual differences in the tendency to behave, think, and feel in certain consistent ways" (Caspi, 1998: p. 312). Temperament is defined as "constitutionally based individual differences in emotional, motor and attentional reactivity and self-regulation. Temperamental characteristics are believed to demonstrate consistency across situations, as well as relative stability over time” (Rothbart \& Bates, 1998: p. 109). Even there is an overlap between temperament and personality, according to De Pauw et al. (2009), personality differs from temperament because it encompasses one's thoughts, beliefs and feelings acquired in the course of time, in addition to one's inherent disposition.

Some authors suggest that research in developmental psychopathology should examine factors of personality in children and adolescents presenting disorders in order to investigate individual differences in (mal)adaptation (Mervielde, De Clercq, De Fruyt, \& Van Leeuwen, 2005): they propose five broadband dimensions to capture their individual differences, extraversion, emotional stability, agreeableness, conscientiousness, and openness. 
It was inspired from the Big Five Model resulting from the identification of five broad underlying factors of structure of personality, found by several sets of researchers, from factor-analyzing of measures of traits of human personality (McCrae \& Costa, 1987). Following the discovery of the convergence of the Lexical Hypothesis, the Five Factors model was developed and stated that personality can be described in terms of five aggregate-level trait descriptors (Caspi, 1998). It distinguished openness to experience, conscientiousness, extraversion, agreeableness and neuroticism that are introduced in assessment instruments for adults (Caspi, 1998). Precursors of this model in children have been studied in the 1990s, from free descriptions by parents about their children; nearly $80 \%$ of these descriptors were related to the five factors (Kohnstamm et al., 1998, Caspi, 1998). These five factors founded the conception of instruments adapted for children, from preschool age: including other-reported questionnaire, the Hierarchical Personality Inventory for Children (HiPICS, Mervielde \& De Fruyt, 1999); Bipolar Rating Scales based on the Five Factor Model (EBMCF, Roskam, De Maere-Gaudissart, \& Vandenplas-Holper, 2000); the M5-PS-45 Questionnaire, (Grist, Socha, \& McCord, 2012); and self-report measures (Measelle, John, Ablow, Cowan, \& Cowan, 2005). What are the particularities of each factor defined by these authors?

- The "Openness to experience" describes children as curious, imaginative, creative, original, adventurous, opened to a variety of experiences, to the novelty; by contrast with closeness, narrow interests, preference for familiarity, resistance to change.

- The "Conscientiousness" (vs. impulsiveness) is characterized as careful, efficient, organized, self-controlling, showing self-discipline, planning, aiming for achievement.

- The "Extraversion" (vs. introversion) corresponds to persons who enjoy being with other people, are full of energy, enthusiastic, action-oriented and they often experience positive emotions and they tend to seek stimulation in the company of others. By contrast, introverts lack the exuberance and show lower activity levels and they are solitary, reserved, tend to be quiet, deliberate, and disengaged from the social world.

- The "agreeableness" (vs. disagreeableness) describes persons who are tendency to be compassionate and cooperative and seek social harmony. They are therefore considerate, friendly, generous, helpful, and they have an optimistic view of human nature. Disagreeable individuals place self-interest above getting along with others and they are generally unconcerned with others' well-being. They could appear cold, unkind, suspicious and antagonistic towards others.

- The "neuroticism" (vs. emotional stability) have tendency to be sensitive, nervous and to experience unpleasant emotions easily, such as anger, anxiety, depression, or vulnerability, so they are emotionally too reactive to events. They could be often in a bad mood. By contrast, individuals who have emotional stability are secure, confident, less easily upset and they tend to be calm and less emotionally reactive.

\subsection{Personality and Temperament in Children with ASD}

Some studies focusing on temperament emphasize that the children with ASD show low level of effortful control than TD children (Jarhomi et al., 2013; Konstantareas \& Stewart, 2006).

Some rare studies investigated personality in children with ASD, based on the five-factor model of personality, including conscientiousness, openness to experience, agreeableness, extraversion, emotional stability. A recent study compared these personality traits in small samples of children with ASD and of typically developing preschoolers, in order to appreciate the potential interest of using a personality measure combined with other diagnostic assessment instruments to establish diagnosis of ASD (Fortenberry, Grist, \& McCord, 2011). These authors emphasized lower ratings of conscientiousness, openness and extraversion in preschoolers with ASD (n $=8$ ), diagnosed using the CARS, than in TD preschoolers ( $n=7)$. Schriber, Robins, \& Solomon (2014) examined whether personality differences exist in children/adolescents with ASD $(n=50)$ and TD controls $(n=50)$ according to self- and parent reports of personality. Individuals with ASD were less conscientious, open to experience, extraverted, agreeable and more neurotic, than TD children.

\section{Links between Personality, Temperament and Emotion Regulation}

Rare are the empirical studies that have explored the relationships or the role of factors of personality and emotion regulation in children with and without developmental disorders. Some studies examined rather the link between temperament and emotion regulation or dysregulation. 


\subsection{Which Links between Personality, Temperament and Emotion Regulation in TD Children?}

According to Eisenberg et al. (2000), both temperament and personality are central in emotionality and regulation processes and their role must be considered in the prediction of the quality of social functioning.

Santucci, Silk, Shaw, Gentzler, Fox, \& Kovacs (2008) examined indices of vagal tone and two dimensions of temperament as predictors of emotion regulation strategies among 4 - 7 years old children $(n=54)$ of mothers with a history of depression and control mothers. They observed children's emotion regulation strategies (adaptive and maladaptive) during a frustration task implicating a delay of gratification in one protocol. In another independent protocol, vagal tone was assessed during rest (baseline), during emotional challenge (reactivity) and post-challenge (recovery). Mothers rated their children's temperament (effortful control, negative affectivity). Lower vagal recovery and higher negative affectivity in temperament were associated with maladaptive emotion regulation responses to frustration. However, vagal tone and temperament were not associated with adaptive emotion regulation responses and the presence of maternal depression did not affect the results. These findings support that vagal tone and temperament are markers of individual differences in emotion regulation.

Recently, Nader-Grosbois \& Mazzone (accepted) showed in TD preschoolers significant links between some factors of personality (particularly agreeableness, emotional stability and extraversion) and scores in emotion regulation or emotion dysregulation. In other words, they emphasized that more the child is agreeable, emotionally stable, extraverted, more he/she is perceived as regulating well one's emotions. If the child is less agreeable, less emotionally stable and more extraverted, the more he/she is perceived as displaying emotion dysregulation. The extraversion was positively linked with scores in emotion regulation and in emotion dysregulation. The regression analyses by stepwise showed that the agreeableness, the emotional stability, and the level of intellectual efficiency explained $49 \%$ of the variance of composite score in emotion regulation; the agreeableness, the extraversion explained $34.8 \%$ of the variance of score in emotion regulation; and the emotional stability, the extraversion and the agreeableness explained $61.3 \%$ of the variance of score in emotion dysregulation.

\subsection{Which Links between Personality, Temperament and Emotion Regulation in Children with ASD?}

Affect regulation in a frustrating situation and temperament (assessed by Children's Behavior Questionnaire, CBQ) were examined in children with ASD (Konstantareas \& Stewart, 2006). They showed greater variability in affect regulation and used less effective affect regulation strategies compared to controls. Among the three temperament factors, only effortful control but not negative affectivity and surgency/extraversion distinguished children with ASD from controls. Garon et al. (2009) investigate early temperamental profiles and their associations with autistic symptoms in high-risk infants with an older sibling with ASD and low-risk infants with no family history of ASD. The children diagnosed with ASD at 36 months are distinguished, from both other groups, by a temperament profile marked by lower positive affect, higher negative affect and difficulty controlling attention and behavior, labeled "Effortful Emotion Regulation" and by a temperament profile of low Behavioral Approach (lower sensitivity to "social" reward cues). Jarhomi et al. (2013) find in children with high functioning autism that the effortful control is positively correlated to emotion regulation; and that the effortful control, and both joint engagement variables, executive function are significant positive predictors of emotion regulation.

In addition, the contents of items in M-CHAT (Robins, Fein, Barton, \& Green, 2001) and in CARS-T (Schopler, Reichler, \& Rochen Renner, 1993) corresponding to specific pathological characteristics of ASD seems to be relatively clearly linked with the five factors of personality, according to Fortenberry et al. (2011: pp. 75-77). These authors present in a Table (p. 76) the matching between each item in M-CHAT, in CARS-T and the corresponding personality factors (including the item named "emotional expression and regulation of emotions" matched with "extraversion").

However, nearly none study focused specifically on the question of links between personality factors and emotion regulation or dysregulation processes in children with ASD.

\section{Objectives of This Study}

The study aims first to explore what are the individual factors linked with emotion regulation and dysregulation, 
and social adjustment in children with ASD. Second, it investigates whether their emotion regulation and dysregulation are linked with social adjustment.

\section{Method}

\subsection{Participants}

The 39 participants were 3 - 12 years old children with ASD (23 boys, 6 girls) recruited in French-speaking Belgian special schools or psycho-medico-social institutions and by contacting an association of parents having a child with ASD. Their diagnoses have been established by multidisciplinary teams in psycho-medico-social centers. Table 1 presents descriptive statistics about their individual characteristics: chronological age, developmental age, level of intellectual efficiency and scores of five factors of personality.

\subsection{Instruments}

6.2.1. Differential Scales of Intellectual Efficiency-Revised Edition (EDEI-R, Perron-Borelli, 1996) These scales were used to estimate children's global developmental age, verbal developmental age and nonverbal developmental age and the level of intellectual efficiency.

\subsubsection{Bipolar Rating Scales Based on the Five Factor Model (EBMCF, Roskam, De Maere-Gaudissart,} \& Vandenplas-Holper, 2000)

This questionnaire measures the child's personality and may be completed by familiar adults (caregivers or teachers). It includes 25 "bipolar" items divided according to the five factors of personality: extraversion, agreeableness, conscientiousness, emotional stability and openness. The items are presented as pairs of adjectives in one hand a positive pole and in the other hand, a negative pole: for example: "shy-self-assured" for the factor "extraversion", "cold-warm" for the factor agreeableness, "careless-careful" for the factor "consciousness", "emotive-impassive" for the factor "emotional stability", "closed mind-interested in everything" for the factor "openness to experience". For each item, a 9-point Likert scale is proposed. The adult attributes the score on this scale that corresponds to the best to the child's characteristics. Higher scores are attributed to positive pole of each scale. For each factor, an average score (varying from 1 to 9 ) is calculated. The validation was made with 321 typically developing children. The internal consistence of the five factors was very good $(\alpha=$ from .70 to .93). Correlations for stability test-retest were highly significant (from .66 to .93 for teachers, from .80 to .89 for caregivers).

6.2.3. Childhood Autism Rating Scale (CARS-T, Schopler, Reichler, \& Rochen Renner, 1993)

This scale is used for assessing the presence and severity of symptoms of ASD in children (from 2 years and

Table 1. Descriptive statistics of participants’ characteristics.

\begin{tabular}{lccc}
\hline & $M$ & SD & Range \\
\hline Chronological age (years) (CA) & 8.44 & 2.11 & $3.10-12$ \\
Chronological age (months) & 101.28 & 25.32 & $37.2-144$ \\
Developmental age (months) (DA) & 53.71 & 9.55 & $37.33-74$ \\
Verbal Developmental age (months) (VDA) & 47.61 & 11.15 & $33-72$ \\
Nonverbal Developmental age (months) (NVDA) & 61.50 & 17.02 & $30-96$ \\
Level of intellectual efficiency & 95.71 & 6.96 & $83-102.33$ \\
Degree of ASD (CARS-T score) & 34.83 & 4.24 & $30-42$ \\
Consciousness & 5.25 & 1.78 & $1.60-8.20$ \\
Openness & 5.20 & 1.76 & $2.80-9$ \\
Agreeableness & 5.24 & 1.69 & $2.20-7.60$ \\
Extraversion & 5.30 & 1.88 & $1.60-8.80$ \\
Emotional stability & 5.28 & 1.33 & $2.80-7.60$ \\
\hline
\end{tabular}


older) and for distinguishing them from other developmentally handicapped children. It helps to determine symptom severity (mild-to-moderate and severe ASD) through quantifiable ratings based on direct observation. The 15 items cover several functional areas: relating to people, imitation, emotional response, body use, object use, adaptation to change and restricted interests, visual response, listening response; taste, smell, and touch response and use, fear or nervousness, verbal communication, nonverbal communication, activity level, level and consistency of intellectual response, general impressions. The professionals rates the child on each item, using a 4 -point response scale $(0=$ normal or appropriate for the child's age, $4=$ severely abnormal). Ratings are based on frequency of the described behavior and also on its intensity, peculiarity, and duration. These CARS categories are scored on a scale of one through four, with half points awarded for those that are between those steps. The Scoring standards are as follows: 1 -within the normal range for child's age, 2-mildly abnormal, 3-moderately abnormal, 4-severely abnormal. The CARS scores range from 15 to 60, and the cutoff point for ASD diagnosis is a score of 30 or above. According to the scoring standards of CARS, scores between 30 and 37 indicate mild to moderate autism and scores between 38 and 60 are characterized as severe autism.

\subsubsection{Emotion Regulation Checklist (ERC, Shields \& Cicchetti, 1997; French-Version, ERC-vf, Nader-Grosbois \& Mazzone, Accepted)}

This questionnaire assesses adult's perception of the child's emotion regulation and emotionality. It consists of 24 items divided in two scales. The "Emotion Regulation" (ER) scale corresponds to appropriate empathy, affective displays and emotional understanding (8 items), for example: "can recover quickly from episodes of upset or distress", "responds positively to neutral or friendly overtures by peers", "is able to delay gratification", "is emphatic towards others, shows concern when others are upset or distressed". The "Lability/Negativity" or "emotion dysregulation" (ED) scale integrates behavior including mood lability, angry reactivity and dysregulated negative affect (16 items), for example: "exhibits wide mood swings", "display flat affect", "responds angrily to limit-setting by adults", "displays negative emotions when attempting engage others in play". Using a 4-point Likert scale, from 1 (never) to 4 (almost always), the adult reports how often the child exhibit behavior described in every item. Three raw scores could be calculated: ER score, ED score and composite score ER (taken into account the scores in both subscales) that are transformed in average scores relative to a maximum score $=4$. This French version ERC-vf (Nader-Grosbois \& Mazzone, accepted) presents a good internal consistency for Emotion Regulation scale $(\alpha=.72)$ and for emotion dysregulation scale $(\alpha=.82)$. The correlation between these two scales is significant and negative $(r=-.66, p<.001)$. Recent studies showed that the ERC is applicable to children presenting developmental psychopathologies, including ASD (Jahromi et al., 2013; Mazzone \& Nader-Grosbois, 2012).

\subsubsection{Social Adjustment Scales (EASE, Hughes, Soares-Boucaud, Hochmann, \& Frith, 1997)}

This scale corresponds to a measure of the adult's perception of the child's socio-emotional adjustment in daily social relationships. The adult referent of the child has to answer 50 items by identifying the extent to which the behavior is usual in the child. 25 items relate to social skills (including items referring to the quality of social relationships), such as respect for social rules or polite behavior (EASE-Social Skills). For example: "uses the conventional polite phrases when we remind him(her)", "follows the simple rules of play without using having to remind him(her)”. 25 other items reflect the adult's perception of the child's capacities to mobilize the understanding of other mental states (ToM) and to adopt another person's perspective (EASE-ToM); they correspond to social behavior involving the consideration of emotions, beliefs and desires in others. For example: "recognizes sadness in others", "is capable of playing a small role". Every item is scored on a 2-point Likert scale, from 0 to $2(0=$ very rare or non-existent behavior; $1=$ relatively frequent behavior; and $2=$ frequent or usual behavior). The total score varies from 0 to 100 points. The two scales presents good internal consistence $(\alpha=.77$ for EASE-Social Skills; $\alpha=.79$ for EASE-ToM) (Hughes et al., 1997; Comte-Gervais, 2008a, 2008b). These authors did not find any examiner effect (Comte-Gervais, 2008a, 2008b).

\subsection{Procedure}

In two individual sessions, the EDEI-R was administered to the children in a quiet room at school or at psychomedico social institution, and more rarely at home. The CARS-T, the EBMCF, the ERC-vf and the EASE were completed by teachers or psycho-educative professionals. 


\section{Results}

\section{Participants' Characteristics}

Table 1 presents means, standard deviations and ranges for chronological age (CA), developmental age (DA), verbal developmental age (VDA), non verbal developmental age (NVDA), level of intellectual efficiency, degree of ASD and scores for the five factors of personality. The intellectual level in these children varies from low level of intelligence to a normal intelligence. The severity of ASD varies from mild to the beginning of severe.

Pearson coefficients of correlation performed between the degree of severity of ASD (CARS-T) and five factors of personality indicate that only emotional stability is significantly and positively correlated with the degree of severity of ASD $(r=.512, p<.001)$

Table 2 presents means, standard deviations and ranges for the three scores of ERC-vf and the two scores of social adjustment (EASE).

Pearson's coefficient of correlations have been calculated between children's characteristics (CA, DA, VDA, the level of intellectual efficiency, degree of ASD and scores in the five factors of personality) and scores in ERC-vf. As indicated in the Table 3, positive and significant correlations are obtained between composite score ER, score ER and VDA. The composite score ER and the score ER are positively and significantly linked with factors of openness, agreeableness, and extraversion. The score ED is negatively and significantly linked with the factor of emotional stability, but positively and significantly linked with extraversion.

Linear regression analyses by the stepwise method were performed in order to verify the extent to which the children's characteristics (CA, DA, VDA, the level of intellectual efficiency, degree of ASD and scores in the five factors of personality) could predict the variance of the three scores of ERC-vf. The Table 4 presents results

Table 2. Descriptive statistics of emotion regulation, emotion dysregulation and social adjustment scores.

\begin{tabular}{lccc}
\hline & $M$ & SD & Range \\
\hline ERC-ER Composite & 2.87 & .34 & $2.30-3.59$ \\
ERC-ER & 2.76 & .53 & $1.63-3.75$ \\
ERC-ED & 2.98 & .40 & $2.40-3.93$ \\
EASE-ToM (\%) & .39 & .24 & $.02-.82$ \\
EASE-Social Skills (\%) & .59 & .21 & $.16-.91$ \\
\hline
\end{tabular}

Note: ERC-ER composite = composite score in emotion regulation ERC; ERC-ER = score in emotion regulation ERC; ERC-ED = score in emotion dysregulation ERC; EASE = social adjustment scale.

Table 3. Correlations between children's characteristics and emotion regulation, emotion dysregulation scores.

\begin{tabular}{lccc}
\hline \multicolumn{1}{c}{ Variables } & ERC-ER composite & ERC-ER & ERC-ED \\
\hline Chronological age (CA) & .000 & .104 & -.138 \\
Developmental age (DA) & .092 & .098 & -.005 \\
Verbal developmental age (VDA) & $.333^{*}$ & $.422^{* *}$ & -.096 \\
Level of intellectual efficiency & .239 & .295 & -.056 \\
Degree of ASD (CARS-T) & .077 & .017 & .118 \\
Consciousness & .291 & .191 & -.241 \\
Openness & $.539^{* * *}$ & $.624^{* * * *}$ & -.063 \\
Agreeableness & $.755^{* * * *}$ & $.713^{* * * *}$ & -.199 \\
Extraversion & $.360^{*}$ & $.733^{* * * *}$ & $.571^{* * * *}$ \\
Emotional stability & .176 & .201 & $-.509^{* * * *}$
\end{tabular}

Note: ERC-ER composite = composite score in emotion regulation ERC; ERC-ER = score in emotion regulation ERC; ERC-ED = score in emotion dysregulation ERC. ${ }^{*} p \leq .05,{ }^{* *} p \leq .01,{ }^{* * *} p \leq 005,{ }^{* * * *} p \leq 001$. 
Table 4. Predictors of emotion regulation and emotion dysregulation.

\begin{tabular}{|c|c|c|c|c|c|}
\hline \multirow[b]{2}{*}{ Predictors } & \multirow[b]{2}{*}{ B } & \multicolumn{4}{|c|}{ Composite score in emotion regulation } \\
\hline & & $\mathrm{SE} / \mathrm{B}$ & BETA & $\mathrm{R}_{\text {adj. }}^{2}$ & $F$ \\
\hline Model 1a & & & & & $23.309^{* * * *}$ \\
\hline \multirow[t]{2}{*}{ Agreeableness } & .293 & .061 & .760 & .553 & \\
\hline & & \multicolumn{4}{|c|}{ Score in emotion regulation } \\
\hline Predictors & $\mathrm{B}$ & $\mathrm{SE} / \mathrm{B}$ & BETA & $\mathrm{R}_{\text {adj. }}^{2}$ & $F$ \\
\hline Model 1b & & & & & $19.593^{* * * *}$ \\
\hline $\begin{array}{c}\text { Extraversion } \\
\text { Model 2b }\end{array}$ & .236 & .053 & .732 & .508 & \\
\hline Extraversion & & & .504 & .665 & $18.892^{* * * *}$ \\
\hline \multirow[t]{2}{*}{ Agreeableness } & & & .468 & & \\
\hline & & \multicolumn{4}{|c|}{ Score in emotion dysregulation } \\
\hline Predictors & B & $\mathrm{SE} / \mathrm{B}$ & BETA & $\mathrm{R}_{\text {adj. }}^{2}$ & $F$ \\
\hline Model 1c & & & & & $8895^{* *}$ \\
\hline Extraversion & .111 & .037 & .586 & .305 & 8.895 \\
\hline Model 2c & & & & & \\
\hline Extraversion & .169 & .032 & .895 & .607 & $14.887^{* * * *}$ \\
\hline Agreeableness & -.132 & .035 & -.634 & & \\
\hline Model 3c & & & & & \\
\hline Extraversion & .147 & .030 & .779 & 683 & $13979^{* * * *}$ \\
\hline Agreeableness & -.130 & .032 & -.622 & .683 & 13.929 \\
\hline Emotional stability & -.084 & .038 & -.312 & & \\
\hline
\end{tabular}

Note: ${ }^{* *} p \leq .01,{ }^{* * * *} p \leq .001$.

of significant predictors of the three scores in ERC-vf, from analyses of linear stepwise regression. The model 1a showed that agreeableness explains $55.3 \%$ of the variance of the composite score ER. The model $2 \mathrm{~b}$ including extraversion and agreeableness explains $66.5 \%$ of the variance of the score ER. The model 3c including extraversion, agreeableness and emotional stability explains $68.3 \%$ of the variance of the score ED.

Pearson's coefficient of correlations have been calculated between children's characteristics (CA, DA, VDA, the level of intellectual efficiency, degree of ASD and scores in the five factors of personality), the three scores in ERC-vf and the two EASE scores (see Table 5). Both EASE-ToM and EASE-Social skills scores are positively and significantly correlated with VDA, the level of intellectual efficiency and also with four factors of personality, consciousness, openness, agreeableness, and extraversion. The composite score ER and the score ER are positively and significantly linked with scores in EASE-ToM and EASE-Social Skills.

Moreover, linear regression analyses by the stepwise method were also performed in order to examine the extent to which the children's characteristics (chronological age, developmental age, verbal developmental age, the level of intellectual efficiency, degree of ASD, scores in the five factors of personality) and their three scores in ERC-vf could predict the variance of the teachers' perceptions of social adjustment assessed by the EASE. The Table 6 presents results of significant predictors of the two scores in social adjustment, EASE-ToM and EASE-Social Skills, from analyses of linear stepwise regression. The model 1d showed that openness explains $55.9 \%$ of the variance of the EASE-ToM score. The model 2e including agreeableness and extraversion explains $61.6 \%$ of the variance of the EASE-Social Skills score.

\section{Discussion and Conclusion}

In preliminary results about the factors of personality, the children with ASD are less positively rated for each five factor, in comparison with TD children assessed in a study using also the EBMCF (Nader-Grosbois \& Mazzone, accepted). So, the children with ASD are perceived as less conscientious, less open to experience, less extraverted, less agreeable and less emotionally stable (or more neurotic) than TD children, as it was also reported by Schriber, et al. (2014), and partially by Fortenberry et al. (2011) (who obtained lower rating only for conscientiousness, openness and extraversion in preschoolers with ASD than in TD preschoolers). The emotional stability is significantly and positively linked to the degree of severity of ASD; as suggested by Fortenberry et al. (2011), specific factors of personality could be matched with some items of instruments assessing specific pathological characteristics of ASD, such as M-CHAT or CARS-T. 
Table 5. Correlations between children’s characteristics, emotion regulation, emotion dysregulation and social adjustment.

\begin{tabular}{lcc}
\hline Variables & EASE-ToM & EASE-Social Skills \\
\hline Chronological age (CA) & .163 & .013 \\
Developmental age (DA) & .185 & .103 \\
Verbal developmental age (VDA) & $.351^{*}$ & $.333^{*}$ \\
Level of intellectual efficiency & $.465^{* *}$ & $.657^{* * * *}$ \\
Degree of ASD (CARS-T) & -.031 & .077 \\
Consciousness & $.549^{* * * *}$ & $.369^{*}$ \\
Openness & $.761^{* * * *}$ & $.708^{* * * *}$ \\
Agreeableness & $.689^{* * * *}$ & $.742^{* * * *}$ \\
Extraversion & $.444^{* *}$ & $.643^{* * * *}$ \\
Emotional stability & .044 & .173 \\
ERC-ER composite & $.811^{* * * *}$ & $.743^{* * * *}$ \\
ERC-ER & $.808^{* * * *}$ & $.859^{* * * *}$ \\
ERC-ED & -.075 & -.158 \\
\hline
\end{tabular}

Note: ERC-ER composite = composite score in emotion regulation ERC; ERC-ER $=$ score in emotion regulation ERC; ERC-ED = score in emotion dysregulation ERC; EASE = social adjustment scale. ${ }^{*} p \leq .05,{ }^{* *} p \leq .01,{ }^{* * *} p \leq .005,{ }^{* * * * *} p \leq .001$.

Table 6. Predictors of social adjustment competences.

\begin{tabular}{|c|c|c|c|c|c|}
\hline \multirow[b]{2}{*}{ Predictors } & \multirow[b]{2}{*}{ B } & \multicolumn{4}{|c|}{ EASE-ToM } \\
\hline & & $\mathrm{SE} / \mathrm{B}$ & BETA & $\mathrm{R}_{\mathrm{adj} .}^{2}$ & $F$ \\
\hline $\begin{array}{l}\text { Model 1d } \\
\text { Openness }\end{array}$ & .103 & .021 & .764 & .559 & $23.813^{* * * *}$ \\
\hline & & \multicolumn{4}{|c|}{ EASE-Social Skills } \\
\hline Predictors & B & SE/B & BETA & $\mathrm{R}_{\text {adj. }}^{2}$ & $F$ \\
\hline $\begin{array}{c}\text { Model 1e } \\
\text { Agreeableness }\end{array}$ & .088 & .019 & .743 & .526 & $21.014^{* * * *}$ \\
\hline $\begin{array}{c}\text { Model 2e } \\
\text { Agreeableness } \\
\text { Extraversion }\end{array}$ & $\begin{array}{l}.067 \\
.040\end{array}$ & $\begin{array}{l}.020 \\
.018\end{array}$ & $\begin{array}{l}.562 \\
.373\end{array}$ & .616 & $15.441^{* * * *}$ \\
\hline
\end{tabular}

Note: EASE = social adjustment scale. ${ }^{* * * *} p \leq .001$.

Concerning the mean scores in emotion regulation (ERC-ER and ERC-ER composite), they are lower for children with ASD in this study, in comparison with those of TD children examined by Nader-Grosbois \& Mazzone (accepted); this difference was also reported by Jahromi et al., 2012, 2013; Konstantareas \& Stewart, 2006). Moreover, mean score and also maximum score in emotion dysregulation are higher in children with ASD than TD children (assessed by Nader-Grosbois \& Mazzone, accepted). This result, joining those of other studies, confirmed the postulate of emotion dysregulation or "functional and developmental dysregulation" affecting socio-emotional abilities in children with ASD (Adrien, 1996, 2005; Cole et al., 1994; DeGangi, 2000; Gomez \& Baird, 2005; Loveland, 2005; Nader-Grosbois, 2011b; Nader-Grosbois et al., 2012; Mazefsky et al., 2013; Prizant et al., 2003; Samson et al., 2014; Trevarthen, 1989; Whitman, 2004).

Which individual factors are linked with emotion regulation or dysregulation in the children with ASD in this study? The children with ASD presenting a higher verbal developmental age are perceived as having better emotion regulation. As Gulsrud et al. (2010) suggested, when the children with ASD presents low expressive language level communication they use less frequently sophisticated verbal strategies of emotion regulation. In TD children, it is also the case, a better verbal developmental age is linked positively with emotion regulation (Nader-Grosbois \& Mazzone, accepted). About the links between personality factors and emotion regulation in children with ASD, correlations show that agreeableness, extraversion, and openness are positively linked with emotion regulation abilities; and regression analyses show that particularly extraversion, agreeableness explained a part of variance of these emotion regulation abilities (as also obtained in TD children, Nader-Grosbois 
\& Mazzone, accepted). In other words, when the children with ASD are perceived as more agreeable, more extravert, and open to experience, they regulate better their emotions and their socio-emotional behavior. Their emotion dyregulation is negatively linked with emotional stability and positively with extraversion (in a similar way than in TD children, however their emotional dysregulation was also correlated negatively with agreeableness, consciousness, Nader-Grosbois \& Mazzone, accepted). Moreover, a part of variance of emotion dysregulation is explained by extraversion (positively), emotional stability and agreeableness (negatively) (as it was also observed in TD children, Nader-Grosbois \& Mazzone, accepted). The children with ASD who are perceived as more extravert, less agreeable, less emotionally stable (or more neurotic) are more emotionally dysregulated. In addition, no significant link was obtained between the degree of severity of ASD and the emotion regulation or dysregulation.

How individual factors and emotion regulation or dysregulation in children with ASD are linked to their social adjustment? The children with ASD presenting a higher verbal developmental age, a higher level of intellectual efficiency are perceived as having better social adjustment. Better emotion regulation is, better the social adjustment is, in the children with ASD (as reported in other studies, Jahromi et al., 2013; Nader-Grosbois et al., 2012; Whitman, 2004; and as also observed in TD children, Nader-Grosbois \& Mazzone, accepted). In other words, the children with ASD who understand cognitively better situations, who communicate better, who regulate better their emotions, are more likely to take the perspective of others, to display adequate social behavior, empathy towards other person and to adjust their behavior according to social rules and conventions in everyday live. However, in this study, no significant link is obtained between emotion dysregulation and social adjustment in children with ASD (as also observed in TD children, Nader-Grosbois \& Mazzone, accepted); and between the degree of severity of ASD and social adjustment scores.

To conclude, this study contributes to the knowledge about the potential role of factors of personality in order to better understand individual differences in emotion regulation and dysregulation processes, and also in their social adjustment in daily life. Indeed, the factors of personality seems to be markers of individual variability in the manner in which the children with ASD regulate their positive and negative emotions, their emotional expressions, their social behavior towards peers and adults, in interactive situations or situations inducing frustration, and the way in which they mobilize their perspective taking abilities and social skills in every day relationships. In future research and in intervention, the impact of personality factors must be considered not only in the approach of emotion regulation or dysregulation processes and of their social (in)abilities but also in the manner in which the parents "socialize emotions" in their children with ASD. Parents could adjust their reactions, their conversations about emotions according to their child's personality, beyond his or her age, gender, level of development, socio-emotional competences.

Our findings emphasize the importance of assessing and of teaching children with ASD to recognize, to regulate their emotions and to diversify their emotion regulation strategies, in taking into account the strengths and weaknesses in their individual personality. Some authors show the interest to assess emotion regulation and dysregulation in pre- and post-training and the positive effect of training emotion regulation strategies in children with ASD. For example, in the SCERTS Model (Prizant et al., 2003), there is an initial assessment of child's capacities to maintain well-regulated states of arousal across contexts, by documenting the primary factors supporting or interfering with emotional regulation, and the specific signals given by the child when he or she needs support. Behavioral signals are categorized according to graduated levels of arousal, ranging from calm and well-regulated to extremely dysregulated. Specific goals are aimed and a plan are developed for supporting the child in acquiring self-regulatory or mutual-regulatory strategies indexed to each level of arousal. As emotional regulatory strategies are implemented, the efficacy of such strategies is documented with adjustments made to the plan as needed. For another example, after a cognitive behavioral intervention training emotion regulation strategies, a decreasing of anger and anxiety was found in 10 - 14 years old children (Sofronoff, Attwood, Hinton, \& Levin, 2007). Experimental studies, cross-sectional studies with greater samples and comparative samples (presenting ASD and other disabilities) and longitudinal studies should pursue to investigate the dynamic between regulation processes, social cognition and social (mal)adjustment, in taking into account both individual and family, educative factors.

\section{Acknowledgements}

The study presented in this paper was led with the support of the Chair Baron Frère in Special Education of the 
Foundation Louvain of the Catholic University of Louvain, Louvain-la-Neuve. The authors thank Dante Cicchetti and Ann Shields for their agreement for the French translation and validation of the Emotion Regulation Checklist.

\section{References}

Adrien, J.-L. (1996). Autisme du jeune enfant. Développement psychologique et trouble de la régulation. Paris: Expansion Scientifique Française, Elsevier.

Adrien, J.-L. (2005). Vers un nouveau modèle de psychopathologie de l'autisme. PsychoMédia, 3, 37-41.

Argott, P., Buffington Townsend, D., Sturmey, P., \& Poulson, C. L. (2008). Increasing the Use of Empathic Statements in the Presence of a Non-Verbal Affective Stimulus in Adolescents with Autism. Research in Autism Spectrum Disorders, 2, 341-352. http://dx.doi.org/10.1016/j.rasd.2007.08.004

Bacon, A. L., Fein, D., Morris, R., Waterhouse, L., \& Allen, D. (1998). The Responses of Autistic Children to the Distress of Others. Journal of Autism and Developmental Disorders, 28, 129-142. http://dx.doi.org/10.1023/A:1026040615628

Baurain, C., \& Nader-Grosbois, N. (2013). Compétences sociales et émotionnelles: Enfant typique et déficient intellectuel. Säarbrucken: Presses Académiques Francophones.

Begeer, S., Koot, H. M., Rieffe, C., Meerum Terwogt, M., \& Stegge, H. (2008). Emotional Competence in Children with Autism. Diagnostic Criteria and Empirical Evidence. Developmental Review, 28, 342-369. http://dx.doi.org/10.1016/j.dr.2007.09.001

Bieberich, A. A., \& Morgan, S. B. (2004). Self-Regulation and Affective Expression during Play in Children with Autism or Down Syndrome: A Short-Term Longitudinal Study. Journal of Autism and Developmental Disorders, 34, 439-448. http://dx.doi.org/10.1023/B:JADD.0000037420.16169.28

Blanc, R., Adrien, J. L., Roux, S., \& Barthélémy, C. (2005). Dysregulation of Pretend Play and Symbolic Communication in Children with Autism. Autism, 9, 229-245. http://dx.doi.org/10.1177/1362361305053253

Brun, P., Nadel, J., \& Mattlinger, M. J. (1998). L’hypothèse émotionnelle dans l'autisme. Psychologie Française, 43, 147156.

Capps, L., Kasari, C., Yirmiya, N., \& Sigman, M. (1993). Parental Perception of Emotional Expressiveness in Children with Autism. Journal of Consulting and Clinical Psychology, 61, 475-484. http://dx.doi.org/10.1037/0022-006X.61.3.475

Caspi, A. (1998). Personality Development across the Life Course. In W. Damon, \& N. Eisenberg (Eds.), Handbook of Child Psychology, Vol. 3 (5th ed., pp. 311-388). New York: John Wiley \& Sons, Inc.

Charman, T., Swettenham, J., Baron-Cohen, S., Cox, A., Baird, G., \& Drew, A. (1998). An Experimental Investigation of Social Cognitive Abilities in Infants with Autism: Clinical Implications. Infant Mental Health Journal, 19, $260-275$. http://dx.doi.org/10.1002/(SICI)1097-0355(199822)19:2<260::AID-IMHJ12>3.0.CO;2-W

Cole, P., Michel, M., \& Teti, L. (1994). The Development of Emotion Regulation and Dysregulation: A Clinical Perspective. Monographs of the Society for Research in Child Development, 59, 73-100. http://dx.doi.org/10.2307/1166139

Comte-Gervais, I., Giron, A., Soares-Boucaud, I., \& Poussin, G. (2008a). Evaluation de l'intelligence sociale chez l'enfant présentant des troubles spécifiques du langage oral. Présentation d'une échelle d'évaluation clinique. L'Evolution Psychiatrique, 73, 353-366. http://dx.doi.org/10.1016/j.evopsy.2008.02.004

Comte-Gervais, I., Giron, A., Soares-Boucaud, I., \& Poussin, G. (2008b). L’évaluation de l'intelligence sociale chez l'enfant. L'Information Psychiatrique, 84, 667-673.

Corona, R., Dissanayake, C., Arbelle, S., Wellington, P., \& Sigman, M. (1998). Is Affect Aversive to Young Children with Autism? Behavioral and Cardiac Responses to Experimenter Distress. Child Development, 69, 1494-1502. http://dx.doi.org/10.1111/j.1467-8624.1998.tb06172.x

Czapinski, P., \& Bryson, S. E. (2003). Reduced Facial Muscle Movements in Autism: Evidence for Dysfunction in the Neuromuscular Pathway? Brain and Cognition, 51, 177-179.

Dawson, G., \& Lewy, H. (1989). Arousal, Attention and Socioemotional Impairments of Individuals with Autism. In G. Dawson (Ed.), Autism: Nature, Diagnosis and Treatment (pp. 49-74). New York: Guilford Press.

Dawson, G., Hill, D., Spencer, A., Galpert, L., \& Watson, L. (1990b). Affective Exchanges between Young Autistic Children and Their Mothers. Journal of Abnormal Child Psychology, 18, 335-345. http://dx.doi.org/10.1007/BF00916569

Dawson, G., Osterling, J., Meltzoff, A. N., \& Kuhl, P. (2000). Case Study of the Development of an Infant with Autism from Birth to Two Years of Age. Journal of Applied Developmental Psychology, 21, 299-313.

http://dx.doi.org/10.1016/S0193-3973(99)00042-8

Dawson, G., Webb, S. J., Carver, L., Panagiotides, H., \& McPartland, J. (2004). Young Children with Autism Show Atypical Brain Responses to Fearful versus Neutral Facial Expressions of Emotion. Developmental Science, 7, 340-359. 
http://dx.doi.org/10.1111/j.1467-7687.2004.00352.x

DeGangi, G. (2000). Pediatric Disorders of Regulation in Affect and Behavior: A Therapist's Guide to Assessment and Treatment. San Diego, CA: Academic Press.

DePauw, S., Mervielde, I., \& Van Leeuwen, K. (2009). How Are Traits Related Problem Behavior in Preschoolers? Similarities and Contrasts between Temperament and Personality. Journal of Abnormal Child Psychology, 37, 309-325. http://dx.doi.org/10.1007/s10802-008-9290-0

Dissanayake, C., Sigman, M., \& Kasari, C. (1996). Long-Term Stability of Individual Differences in the Emotional Responsiveness of Children with Autism. Journal of Child Psychology and Psychiatry, 37, 461-467. http://dx.doi.org/10.1111/j.1469-7610.1996.tb01427.x

Downs, A., \& Smith, T. (2004). Emotional Understanding, Cooperation, and Social Behavior in High-Functioning Children with Autism. Journal on Autism and Developmental Disorders, 34, 625-635. http://dx.doi.org/10.1007/s10803-004-5284-0

Eisenberg, N., \& Spinrad, T. L. (2004). Emotion-Related Regulation: Sharpening the Definition. Child Development, 75 , 334-339. http://dx.doi.org/10.1111/j.1467-8624.2004.00674.x

Eisenberg, N., Fabes, R. A., Guthrie, I. K., \& Reiser, M. (2000). Dispositional Emotionality and Regulation: Their Role in Predicting Quality of Social Functioning. Journal of Personality and Social Psychology, 78, 136-157.

http://dx.doi.org/10.1037/0022-3514.78.1.136

Fortenberry, C. L., Grist, C. L., \& McCord, D. M. (2011). Personality Trait Differences between Typically Developing Children and Those Diagnosed with Autism Spectrum Disorder. Individual Differences Research, 9, 73-83.

Garon, N., Bryson, S. E., Zwaigenbaum, L., Smith, I. M., Brian, J., Roberts, W., \& Szatmari, P. (2009). Temperament and Its Relationship to Autistic Symptoms in a High-Risk Infant Sib Cohort. Journal of Abnormal Child Psychology, 37, 59-78. http://dx.doi.org/10.1007/s10802-008-9258-0

Gattegno, M. P., Abenhaim, N., Kremer, A., Castro, C., \& Adrien, J. L. (2006). Etude longitudinale du développement cognitive et social d'un enfant autiste bénéficiant du programme IDDEES. Journal de Thérapie Comportementale et Cognitive, 16, 157-168. http://dx.doi.org/10.1016/S1155-1704(06)70214-2

Gomez, C. R., \& Baird, S. (2005). Identifying Early Indicators for Autism in Self Regulation Difficulties. Focus on Autism and Other Developmental Disabilities, 20, 106-116. http://dx.doi.org/10.1177/10883576050200020101

Grist, C. L., \& McCord, D. M. (2010). Individual Differences in Preschool Children: Temperament or Personality? Infant and Child Development, 19, 264-274.

Grist, C. L., Socha, A., \& McCord, D. M. (2012). The M5-PS-45: A Five-Factor Personality Questionnaire for Preschool Children. Journal of Personality Assessment, 94, 287-295. http://dx.doi.org/10.1080/00223891.2011.653063

Gross, J. J., \& Thompson, R. A. (2007). Emotion Regulation: Conceptual Foundations. In J. J. Gross (Ed.), Handbook of Emotion Regulation (pp. 3-24). New York: Guilford Press.

Gulsrud, A. C., Jahromi, L. B., \& Kasari, C. (2010). The Co-Regulation of Emotions between Mothers and Their Children with Autism. Journal of Autism and Developmental Disorders, 40, 227-237. http://dx.doi.org/10.1007/s10803-009-0861-x

Hobson, R. P. (1993). Autism and the Development of Mind. Hillsdale, NJ: Erlbaum.

Hobson, R. P., \& Lee, A. (1998). Hello and Goodbye: A Study of Social Engagement in Autism. Journal of Autism and Developmental Disorders, 28, 117-127. http://dx.doi.org/10.1023/A:1026088531558

Hudry, K., \& Slaughter, V. (2009). Agent Familiarity and Emotional Context Influence the Everyday Empathic Responding of Young Children with Autism. Research in Autism Spectrum Disorders, 3, 74-85. http://dx.doi.org/10.1016/j.rasd.2008.04.004

Hughes, C., Soares-Boucaud, I., Hochman, J., \& Frith, U. (1997). Social Behaviour in Pervasive Developmental Disorders: Effects of Informants Group and “Theory of Mind”. European Child and Adolescent Psychiatry, 6, 191-198.

Jahromi, L. B., Bryce, C. I., \& Swanson, J. (2013). The Importance of Self-Regulation for the School and Peer Engagement of Children with High-Functioning Autism. Research in Autism Spectrum Disorders, 7, 235-246. http://dx.doi.org/10.1016/j.rasd.2012.08.012

Jahromi, L. B., Meek, S. E., \& Ober-Reynolds, S. (2012). Emotion Regulation in the Context of Frustration with High Functioning Autism and Their Typical Peers. Journal of Child Psychology and Psychiatry, 53, 1250-1258. http://dx.doi.org/10.1111/j.1469-7610.2012.02560.x

Kasari, C., \& Sigman, M. (1996). Expression and Understanding of Emotion in Atypical Development: Autism and Down Syndrome. In M. Lewis, \& M. W. Sullivan (Eds.), Emotional Development in Atypical Children (pp. 109-130). Mahwah, NJ: Lawrence Erlbaum Associates.

Kasari, C., Sigman, M., \& Yirmiya, N. (1993). Focused and Social Attention of Autistic-Children in Interactions with Familiar and Unfamiliar Adults: A Comparison of Autistic, Mentally-Retarded, and Normal-Children. Development and Psychopathology, 5, 403-414. http://dx.doi.org/10.1017/S0954579400004491 
Kasari, C., Sigman, M., Mundy, P., \& Yirmiya, N. (1990). Affective Sharing in the Context of Joint Attention Interactions of Normal, Autistic, and Mentally Retarded Children. Journal of Autism and Developmental Disorders, 20, 87-100. http://dx.doi.org/10.1007/BF02206859

Kohnstamm, G. A., Halverson Jr., C. F., Mervielde, I., \& Havill, V. L. (1998). Parental Descriptions of Child Personality: Developmental Antecedents of the Big Five. London: Lawrence Erlbaum.

Konstantareas, M. M., \& Stewart, K. (2006). Affect Regulation and Temperament in Children with Autism Spectrum Disorder. Journal of Autism and Developmental Disorders, 36, 143-154. http://dx.doi.org/10.1007/s10803-005-0051-4

Lacroix, A., Guidetti, M., Rogé, B., \& Reilly, J. (2009). Recognition of Emotional and Nonemotional Facial Expressions: A Comparison between Williams Syndrome and Autism. Research in Developmental Disabilities, 30, 976-985. http://dx.doi.org/10.1016/j.ridd.2009.02.002

Litty, C. G. (2007). Temperament and Personality in Preschoolers: Are the Concepts the Same or Different. Ph.D. Dissertation. http://etd.utk.edu/2007/LittyCathy.pdf

Loveland, K. A. (2005). Social-Emotional Impairment and Self-Regulation in Autism Spectrum Disorders. In J. Nadel, \& D. Muir (Eds.), Emotional Development: Recent Research Advances (pp. 365-382). Oxford: University Press.

Loveland, K. A., Tunali-kotoski, B., Pearson, D. A., Brelsford, K. A., Ortegon, J., \& Chen, R. (1994). Imitation and Expression of Facial Affect in Autism. Development and Psychopathology, 6, 433-444. http://dx.doi.org/10.1017/S0954579400006039

Mazefsky, C. A., Herrington, J., Siegel, M., Scarpa, A., Maddox, B. B., Scahill, L., \& White, S. W. (2013). The Role of Emotion Regulation in Autism Spectrum Disorder. Journal of the American Academy of Child \& Adolescent Psychiatry, 52, 679-688. http://dx.doi.org/10.1016/j.jaac.2013.05.006

Mazzone, S., \& Nader-Grosbois, N. (2014). La socialisation parentale des émotions. Etude de cas sur les stratégies de parents d'enfants présentant un trouble du spectre autistique. In J. C. Kalubi, M. Tremblay, H. Gascon, \& J. M. Bouchard (Eds.), Recherche, droits et gouvernance en faveur de la personne et de ses proches. Actes du XIIe Congrès AIRHM Québec 2012 (pp. 207-218). Montréal: Les Éditions de la collectivité.

McCrae, R. R., \& Costa, P. T. (1987). Validation of the Five-Factor Model of Personality across Instruments and Observers. Journal of Personality and Social Psychology, 52, 81-90. http://dx.doi.org/10.1037/0022-3514.52.1.81

McGovern, C. W., \& Sigman, M. (2005). Continuity and Change from Early Childhood to Adolescence in Autism. Journal of Child Psychology and Psychiatry, 46, 401-408. http://dx.doi.org/10.1111/j.1469-7610.2004.00361.x

Measelle, J. R., John, O. P., Ablow, J. C., Cowan, P. A., \& Cowan, C. P. (2005). Can Children Provide Coherent, Stable and Valid Self-Reports on the Big Five Dimensions? A Longitudinal Study from Ages 5 to 7. Journal of Personality and Social Psychology, 89, 90-106. http://dx.doi.org/10.1037/0022-3514.89.1.90

Mervielde, I., \& De Fruyt, F. (1999). The Construction of the Hierarchical Personality Inventory for Children (HiPICS). In I. Mervielde, I. Deary, F. De Fruyt, \& F. Ostendorf (Eds.), Personality Psychology in Europe. Proceedings of the Eight European Conference on Personality Psychology (pp. 107-127). Tilburg: Tilburg University Press. http://hdl.handle.net/1854/LU-119616

Mervielde, I., De Clercq, B., De Fruyt, F., \& Van Leeuwen, K. (2005). Temperament, Personality, and Developmental Psychopathology as Childhood Antecedents of Personality Disorders. Journal of Personality Disorders, 19, 171-201. http://dx.doi.org/10.1521/pedi.19.2.171.62627

Nadel, J., Croué, S., Mattlinger, M. J., Canet, P., Hudelot, C., Lécuyer, C., \& Martini, M. (2000). Do Children with Autism Have Expectancies about Social Behaviour of Unfamiliar People? Autism, 4, 133-145. http://dx.doi.org/10.1177/1362361300004002003

Nader-Grosbois, N. (2007). L’autorégulation et la dysrégulation chez des enfants autistes en situation d'évaluation développementale. Revue Francophone de la Déficience Intellectuelle, 17, 34-52.

Nader-Grosbois, N. (2011a). Théorie de l'esprit: Entre cognition, émotion et adaptation sociale. Bruxelles: De Boeck.

Nader-Grosbois, N. (2011b). Self-Regulation, Dysregulation, Emotion Regulation and Their Impact on Cognitive and Socio-Emotional Abilities in Children and Adolescents with Autism Spectrum Disorders. In T. Williams (Ed.), Autism Spectrum Disorders: From Genes to Environment (pp. 243-286). Rijeka: Intech Open access Publishers.

Nader-Grosbois, N. (2012). Régulation émotionnelle chez l’enfant à développement atypique. In M. Mikolajczak, \& M. Desseilles (Eds.), Traité sur la régulation émotionnelle (pp. 459-472). Bruxelles: De Boeck.

Nader-Grosbois, N., \& Day, J. (2011). Emotional Cognition: Theory of Mind and Face Recognition. In J. Matson, \& P. Sturney (Eds.), International Handbook of Autism and Pervasive Developmental Disorders (pp. 127-157). New York: Springer.

Nader-Grosbois, N., \& Mazzone, S. (accepted). Validation de la version francophone de l'Emotion Regulation Checklist (ERC-vf). Revue Européenne de Psychologie Appliquée. 
Nader-Grosbois, N., Baurain, C., \& Mazzone, S. (2012). Emotion Regulation, Social Cognition and Social Adjustment: Specificities in Children with Autism Spectrum Disorder. In C. E. Richardson, \& R. A. Wood (Eds.), Autism Spectrum Disorders: New Research (pp. 1-39). Hauppauge, NY: Nova Science Publishers.

Perron-Borelli, M. (1996). Échelles Différentielles d'Efficiences Intellectuelles. Forme Révisée (EDEI-R). Paris: Éditions et Applications Psychologiques.

Prizant, B. M., Wetherby, A. M., Rubin, E., \& Laurent, A. C. (2003). The SCERTS Model: A Transactional, Family-Centered Approach to Enhancing Communication and Socioemotional Abilities of Children with Autism Spectrum Disorder. Infants and Young Children, 16, 296-316. http://dx.doi.org/10.1097/00001163-200310000-00004

Remy, S. (2013). Les enfants autistes dysrégulés peuvent-ils évoluer à l'école? Les Cahiers du Diplôme d'Etat de Psychologie Scolaire de l'Université Paris Descartes. http://lescahiersdudeps.wordpress.com/

Robins, D., Fein, D., Barton, M., \& Green, J. (2001). The Modified-Checklist for Autism in Toddlers (M-CHAT): An Initial Investigation in the Early Detection of Autism and Pervasive Developmental Disorders. Journal of Autism and Developmental Disorders, 31, 131-144. http://dx.doi.org/10.1023/A:1010738829569

Roskam, I., de Maere-Gaudissart, A., \& Vandenplas-Holper, C. (2000). Mise au point d'un instrument d'évaluation de la personnalité des enfants à partir du Modèle à Cinq Facteurs. L'Orientation Scolaire et Professionnelle, 29, 661-672.

Rothbart, M. K., \& Bates, J. E. (1998). Temperament. In W. Damon (Series Ed.) \& N. Eisenberg (Vol. Ed.), Social, Emotional, and Personality Development: Vol. 3. Handbook of Child Psychology (pp. 105-176). New-York: Wiley.

Saarni, C. (1999). The Development of Emotional Competence. New York: Guilford Press.

Samson, A. C., Phillips, J. M., Parker, K. J., Shah, S., Gross, J. J., \& Hardan, A. Y. (2014). Emotion Dysregulation and the Core Features of Autism Spectrum Disorder. Journal of Autism and Developmental Disorders, 44, 1766-1772.

Santucci, A. K., Silk, J. S., Shaw, D. S., Gentzler, A., Fox, N. A., \& Kovacs, M. (2008). Vagal Tone and Temperament as Predictors of Emotion Regulation Strategies in Young Children. Developmental Psychobiology, 50, 205-216. http://dx.doi.org/10.1002/dev.20283

Scambler, D. J., Hepburn, S., Rutherford, M. D., Wehner, E. A., \& Rogers, S. J. (2007). Emotional Responsivity in Children with Autism, Children with Other Developmental Disabilities, and Children with Typical Development. Journal of Autism and Developmental Disorders, 37, 553-563. http://dx.doi.org/10.1007/s10803-006-0186-y

Schopler, E., Reichler, R., \& Rochen Renner, B. (1993). Childhood Autism Rating Scale. Los Angeles, CA: Western Psychological Services.

Schriber, R. A., Robins, R. W., \& Solomon, M. (2014). Personality and Self-Insight in Individuals with Autism Spectrum Disorder. Journal of Personality and Social Psychology, 106, 112-130. http://dx.doi.org/10.1037/a0034950

Seynhaeve, I., \& Nader-Grosbois, N. (2008). Sensorimotor Development and Dysregulation of Activity in Young Children with Autism and with Intellectual Disabilities. Research in Autism Spectrum Disorders, 2, 46-59. http://dx.doi.org/10.1016/j.rasd.2007.03.001

Seynhaeve, I., Nader-Grosbois, N., \& Dionne, C. (2008). Functional Abilities and Neuropsychological Dysfunctions in Young Children with Autism and with Intellectual Disabilities. ALTER-European Journal of Disability Research, 2, 230252. http://dx.doi.org/10.1016/j.alter.2008.05.001

Shields, A., \& Cicchetti, D. (1997). Emotion Regulation among School-Age Children: The Development and Validation of a New Criterion Q-Sort Scale. Developmental Psychology, 33, 906-916. http://dx.doi.org/10.1037/0012-1649.33.6.906

Sigman, M. D., Kasari, C., Kwon, J. H., \& Yirmiya, N. (1992). Responses to the Negative Emotions of Others by Autistic, Mentally Retarded, and Normal Children. Child Development, 63, 796-807. http://dx.doi.org/10.2307/1131234

Sofronoff, K., Attwood, T., Hinton, S., \& Levin, I. (2007). A Randomized Controlled Trial of a Cognitive Behavioural Intervention for Anger Management in Children Diagnosed with Asperger Syndrome. Journal of Autism and Developmental Disorders, 37, 1203-1214. http://dx.doi.org/10.1007/s10803-006-0262-3

Southam-Gerow, M., \& Kendall, P. (2002). Emotion Regulation and Understanding: Implication for Child Psychopathology and Therapy. Clinical Psychology Review, 22, 189-222. http://dx.doi.org/10.1016/S0272-7358(01)00087-3

Tardif, C., Lainé, F., Rodriguez, M., \& Gepner, B. (2007). Slowing Down Presentation of Facial Movements and Vocal Sounds Enhances Facial Expression Recognition and Induces Facial-Vocal Imitation in Children with Autism. Journal of Autism and Developmental Disorders, 37, 1469-1484. http://dx.doi.org/10.1007/s10803-006-0223-X

Thompson, R. (1994). Emotion Regulation: A Theme in Search of Definition. In N. Fox (Ed.), The Development of Emotion Regulation: Biological and Behavioral Considerations. Monographs of the Society for Research in Child Development, Vol. 59 (pp. 25-52). Chicago: University of Chicago Press.

Travis, L., Sigman, M., \& Ruskin, E. (2001). Links between Social Understanding and Social Behavior in Verbally Able Children with Autism. Journal of Autism and Developmental Disorders, 31, 119-130.

http://dx.doi.org/10.1023/A:1010705912731 
Trevarthen, C. (1989). Les relations entre autisme et le développement socioculturel normal: Arguments en faveur d'un trouble primaire de la régulation du développement cognitif par les émotions. In G. Lelord, J. P. Muh, M. Petit, \& D. Sauvage (Eds.), Autismes et troubles du développement global de l'enfant (pp. 56-80). Paris: Expansion Scientifique Française.

Werner, K., \& Gross, J. J. (2010). Emotion Regulation and Psychopathology: A Conceptual Framework. In A. M. Kring, \& D. M. Sloan (Eds.), Emotion Regulation and Psychopathology: A Transdiagnostic Approach to Etiology and Treatment (pp. 13-37). New York: Guilford Press.

Whitman, T. (2004). The Development of Autism: A Self-Regulatory Perspective. New-York: Jessica Kingsley Publishers.

Yirmiya, N., Kasari, C., Sigman, M., \& Mundy, P. (1989). Facial Expressions of Affect in Autistic, Mentally Retarded and Normal Children. Journal of Child Psychology and Psychiatry, 30, 725-735. http://dx.doi.org/10.1111/j.1469-7610.1989.tb00785.x

Yirmiya, N., Sigman, M. D., Kasari, C., \& Mundy, P. (1992). Empathy and Cognition in High-Functioning Children with Autism. Child Development, 63, 150-160. http://dx.doi.org/10.2307/1130909 
Scientific Research Publishing (SCIRP) is one of the largest Open Access journal publishers. It is currently publishing more than 200 open access, online, peer-reviewed journals covering a wide range of academic disciplines. SCIRP serves the worldwide academic communities and contributes to the progress and application of science with its publication.

Other selected journals from SCIRP are listed as below. Submit your manuscript to us via either submit@scirp.org or Online Submission Portal.
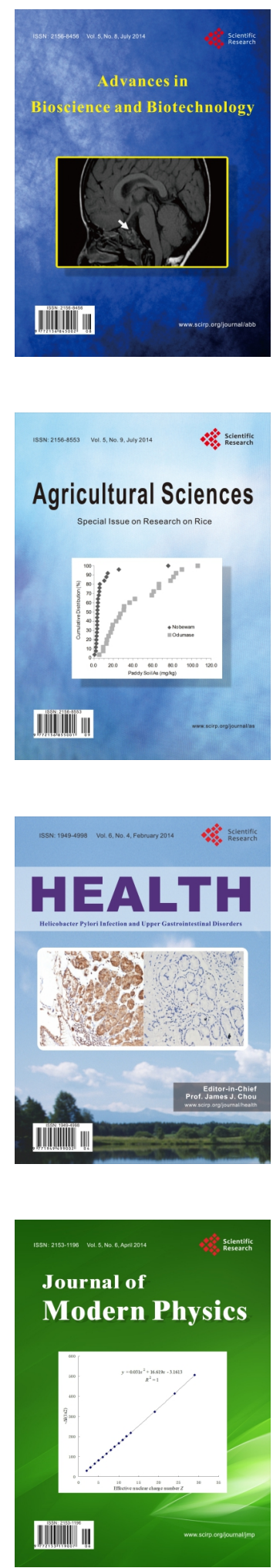
